\title{
The Relationship Between International Study Tour Effects and the Personality Variables of Self-Monitoring and Core Self-Evaluations
}

\section{J. K I i n e H a r rison}

Wake Forest University

Over the past fifteen years, at least a dozen articles have appeared in the management and marketing literature describing and supporting international study tours as valuable educational experiences. These articles, however, have focused primarily on the design and implementation of such tours, with minimal emphasis given to outcome assessments or analysis. This limited attention to empirical support for these programs is surprising given their increasing popularity, especially among business students ("Business Students Flock," 2002). The purpose of this article is to extend the existing literature by assessing the effects of an international business study tour in terms of participants' perceived cross-cultural connectivity and professional development, and then examining those results in light of two personality traits among participants — self-monitoring and core self-evaluations.

Reaction measures from study tour participants were strong, indicating that the tours were effective in facilitating cultural connectivity and enhancing professional development; however, only self-monitoring proved to have a significant impact on both these measures. Nevertheless, post hoc analysis did reveal that a subfactor of core self-evaluations (labeled core self-determination) had a significant impact on professional development. These findings support the value of study tours as positive and beneficial learning experiences for participants. Furthermore, they suggest that self-monitoring capabilities may inform the selection and/or training of study tour participants.

\section{International Study Tours}

Among US students studying abroad, those focusing on business and management represent the second highest percentage (18\%), totaling over 28,000 in 2002. (Note: Students focusing on the Social Sciences represent the highest percentage (22\%), totaling over 35,000.) Further, since 1995, 
the number of US students studying abroad on sojourns less than eight weeks (e.g., study tours) has more than doubled ("American Students Study Abroad," 2004). As an increasing number of business students take advantage of international study tours, greater attention should be given to maximizing the potential value to participants, as well as gaining a better understanding of what may cause some participants to benefit more significantly than others.

Despite differences in scope and content, business study tours are typically described as limited sojourns of 2-4 weeks (Duke, 2000) in which participants travel throughout a selected region (Gordon and Smith, 1992; Schuster, 1993), visiting a variety of business firms and attending presentations by representatives of those firms (Porth, 1997). Rarely does an actual business tour extend beyond four weeks, although some programs are longer when taking into account pre- and post-tour sessions on campus. For example, Porth (1997) and Schuster (1993) each describe three phases in which the first phase focuses on a pre-departure orientation, the second phase consists of on-site business visits during the tour, and the third phase involves post-trip debriefings, discussions, and deliverables. Although Brokaw (1996) advocates an immersion experience in a single location over a multi-city broad-brush, experience, most programs reported in the literature favor the opportunity for cross-cultural comparisons provided by visits to multiple destinations. For example, the business study tour described in the following two paragraphs has been offered by the author since 1994 and is consistent with most programs described in the literature.

Offered during the first summer session of each academic year, the author's International Business Study Tour provides students with an exposure to and understanding of the distinctive characteristics of global business operations. Through various site visits and presentations across Western Europe, each of the functional areas of business (marketing, operations, finance, human resource management, information systems, and strategic management) is covered. Participating organizations include US firms operating abroad as well as foreignowned firms within the different countries. Host organizations in the past have included among others: Goldman-Sachs in London; UPS in Brussels; AON in Amsterdam; Johnson \& Johnson in Paris; Japan Tobacco International in Geneva; Bayer in Cologne; and Audi in Munich.

The course is limited to 14 students, who (with rare exceptions) are entering their last year of study in the business school. Background readings and an orientation session are required prior to departure, with various assignments during and after the tour. These assignments are designed to facilitate active learning and include the following: a profile of one of the host companies 
[presented at orientation] ( $5 \%$ of the course grade); a reflection paper on cultural similarities and differences experienced during the trip (5\%); a marketing portfolio (including a paper and pictures) on comparisons of advertising and branding across countries (20\%); a report on multinational merchant reactions to a single, prevailing business issue (10\%); and an integrated paper reflecting the information and insights gained from the presentations by executives and firms (35\%). The remaining $25 \%$ of the course evaluation is based on participation in class, displayed professionalism at meetings, and conduct throughout the trip. Upon successful completion of the course, participants earn three credit hours towards their business elective requirements.

The value of experiential or active learning through study tours, such as the aforementioned, has been documented in the literature. According to Allen and Young (1997, p. 169), “... learning occurs more readily when students are able to experience (i.e., see, smell, taste, hear, feel) stimuli and actively participate in the education process." By experiencing a culture firsthand, study tour participants develop a much deeper understanding of and appreciation for that culture than they would by simply reading about it (Brokaw, 1996; Porth, 1997). Furthermore, by complementing background readings and lectures with company visits and guest speakers, they are able to observe, question, and discuss various principles of international business, thus leading to more active learning (Duke, 2000; Gordon and Smith, 1992).

Despite the proclaimed value of short-term sojourns, a literature review revealed only one article in which learning outcomes from a business study tour were assessed. Schuster (1993) reported on the largest, significant attitude changes she found among participants for both an Asian study tour and a European study tour. She noted:

In general, after the trip participants believed that entering foreign markets was not as difficult as originally thought, trade barriers are less troublesome than previously perceived, they would be comfortable being part of their company's team to set up business in that market, and they would feel comfortable developing company strategy to compete in that market (Schuster, 1993:58).

The lack of additional empirical evidence on the effectiveness of business study tours is unfortunate, especially given the (mis)perceptions about their academic value. Porter (1997) notes that, despite the growth of these programs, there remains a healthy skepticism about their academic rigor. Therefore, to minimize these concerns, research is needed to support the educational effectiveness of this 
form of experiential learning. The potential value can be demonstrated by the degree of participants' cross-cultural connectivity (as reflected in host-country interactions and assimilation) and by the extent of their professional development (as reflected in global business awareness and appreciation). Furthermore, increased understanding of specific personality traits that may impact students' connectivity and development can better inform participant selection and/or training. With better-suited and better-prepared participants, the likelihood of more positive outcomes and perceptions of international study tours can be increased greatly.

\section{Personality variables}

Two personality variables which have been investigated in the crosscultural literature on expatriates are self-monitoring and core self-evaluations. Given the positive relationship between these traits and expatriates' skills in cross-cultural adjustment and performance, it seems appropriate to extend the current research to focus on how these variables might also impact the attitudes and behaviors of more short-term sojourners such as those on study tours. In the following paragraphs, each personality trait will be defined and discussed, along with the associated cross-cultural research.

\section{S e I f - M o n i t or i ng}

Drawing from theories of impression management, the concept of selfmonitoring was introduced 30 years ago by Snyder $(1974,1987)$ as a social psychological construct reflecting self-observation and self-control guided by situational cues to social appropriateness. Since then, it has become one of the most widely used personality measures for research purposes (Day, Schleicher, Unckless, and Hiller, 2002).

Snyder (1974) defines self-monitoring as an individual's ability to adjust his or her behavior to external, situational factors. An assumption underlying this construct is that people differ in terms of how they monitor (i.e., observe, regulate, and control) the public image they display in social settings and interpersonal relationships (Day et al., 2002; Snyder, 1987). Individuals who are particularly sensitive or alert to social cues that indicate appropriate or desirable social behaviors and who then use these cues to modify their own behavior or presentation are termed "high self-monitors." In contrast, "low self-monitors" are less sensitive or alert to social cues and are more likely to behave in ways that reflect their personal dispositions, internally held beliefs, options, and attitudes, regardless of situational demands (Caligiuri and Day, 2000; O'Cass, 2000; Shuptrine, Bearden, and Teel, 1990; and Snyder and Monson, 1975). 
Hence, high self-monitors seek to create images appropriate to a particular situation in an attempt to be "the right person in the right place at the right time," whereas low self-monitors consistently follow the injunction, "To thine own self be true" (Snyder, 1987).

Research suggests that self-monitoring is a personality trait that remains stable throughout one's life (Jenkins, 1993). Furthermore, it is deemed to be a unique psychological construct, separate and distinct from seemingly related psychological concepts. For example, research has shown that it is not significantly correlated with other personality traits such as self-esteem, locus of control, neuroticism, and achievement anxiety (Snyder, 1987).

Self-monitoring has been linked, however, with certain behavioral strategies, such as uncertainty reduction. Based on research focused on how informative both formal and informal situations are in reducing uncertainty, Berger and Douglas (cited in Gudykunst, Yang, and Nishida, 1987) found that low self-monitors perceive formal situations as more informative, whereas high self-monitors see informal situations as more informative. Similarly, Ickes and Barnes (1977) found that high self-monitors initiate and regulate conversations more than low self-monitors. Research by Gudykunst and his associates (cited in Gudykunst et al., 1987) revealed that this link between self-monitoring and uncertainty reduction extends to cross-cultural situations as well.

Other research on self-monitoring in the cross-cultural context has found that high self-monitors are more willing, and perhaps better able, to adapt their behaviors to those of a host country than are low self-monitors (Caligiuri and Day, 2000). As a result, expatriates also report greater adjustment to their host culture (Harrison, Chadwick, and Scales, 1996). It seems that high self-monitors are generally more adept at boundary-spanning than their counterparts (Caldwell and O'Reilly, 1982).

Given that students on international study tours are "temporary expatriates," it seems reasonable to expect outcomes similar to those of typical expatriates. Hence, students who are high self-monitors presumably should more readily make cross-cultural connections by seeking out local nationals with whom to interact and by assimilating into local cultures with greater ease. Furthermore, given that the research on self-monitoring provides compelling arguments linking the construct with a range of job outcomes (e.g., workplace performance, leadership emergence, and information management) (Mehra, Kilduff and Brass, 2001), it seems reasonable to conclude that high self-monitors would report more positive outcomes associated with activities and benefits related to their professional development. Therefore, it is hypothesized that: 
Hypothesis 1: Compared to lower self-monitoring participants, high selfmonitoring participants will demonstrate greater cross-cultural connectivity during an international business study tour.

Hypothesis 2: Compared to lower self-monitoring participants, high selfmonitoring participants will experience greater professional development related to an international business study tour.

\section{Core SeIf - Evaluations}

The concept of core evaluations as a personality trait was first introduced by Packer (1985), who defined them as "basic conclusions, bottom-line evaluations, that we all hold subconsciously. These evaluations pertain to three fundamental areas of every person's life: self, reality, and other people" (p. 3). Judge and his associates (e.g., Judge, Locke, and Durham, 1997; Judge, Locke, Durham, and Kluger, 1998; and Judge, Erez, Bono, and Thoresen, 2003) continued Packer's research by focusing on core evaluations of the self specifically. Drawing from the personality literature, they present core self-evaluations as a basic, fundamental appraisal of one's personal worthiness, effectiveness and capability as indicated by the personality traits of self-esteem, neuroticism, generalized self-efficacy, and locus of control (Judge et al., 2003).

Self-esteem is the overall value that one places on oneself as a person (Harter, 1990) and is reflected in self-liking, self-worth, and self-pride. Research has shown that this evaluation of oneself remains relatively stable from the time of adolescence and is not easily altered (Tharenou, 1979). The converse of selfesteem is neuroticism, which represents the tendency to exhibit poor emotional adjustment. Individuals who evaluate themselves as neurotic tend to be very anxious, insecure, and hostile (Boudreau, Boswell, Judge, and Bretz, 2001). Generalized self-efficacy is an evaluation of one's ability to perform well across a variety of situations and to cope with life's demands (Judge et al., 1998, 2003). Similar to self-esteem, research suggests that this trait is a subconsciously generalized conclusion drawn from a small number of early life experiences (Judge et al., 1998). The remaining personality trait is locus of control. This trait concerns beliefs about control over events. Individuals with an internal locus of control believe that they control events in their lives, whereas those with an external locus believe that the environment or fate controls events. Consistent with the research on self-esteem and generalized self-efficacy, these control beliefs are subconsciously developed at an early age, later becoming generalized and fundamental characteristics (Judge et al., 1997). 
According to Judge et al., (1998), all of the aforementioned traits reflect a broad, latent higher-order concept that is common to the four. Because each lower-order trait represents a global evaluation of oneself or one's relationship to the environment and because all of them load on a common factor, they are deemed reflections of a single, fundamental dimension labeled core self-evaluations (Judge et al., 1998). Hence, high self-esteem (and low neuroticism), high generalized self-efficacy, and an internal locus of control result from a broad, general, positive self-regard as characterized by high core self-evaluations (Judge et al., 2003).

A review of the literature found only one article investigating the trait of core self-evaluations in a cross-cultural context. Johnson, Krist Of-Brown, Van Vianen, De Pater, and Rigsby (2002) investigated the role of this trait among 178 expatriates in forming social networks during their international assignments in the Netherlands. They found that expatriates with high core self-evaluations were likely to form more social connections than those with lower core self-evaluations. The authors also suggest that this higher-order trait may be useful in the selection of potential expatriates.

As suggested previously, students on international study tours may be considered "temporary expatriates" and should, presumably, demonstrate results consistent with those of typical expatriates. Hence, students with positive core self-evaluations should feel very comfortable and competent in making cross-cultural connections by actively interacting with local nationals and/or assimilating into the local culture. Furthermore, given people with positive core self-evaluations see their work as important (Judge et al., 1997), it seems reasonable to conclude that like-minded students would view the study tour as important and valuable to their professional development. Therefore, it is hypothesized that:

Hypothesis 3: Compared to participants with lower core self-evaluations, participants with high core self-evaluations will demonstrate greater crosscultural connectivity during an international business study tour.

Hypothesis 4: Compared to participants with lower core self-evaluations, participants with high core self-evaluations will experience greater professional development related to an international business study tour. 


\section{M e t hod}

\section{Respondents}

This study was conducted among undergraduate alumni from a small, private university in the southeastern United States. A sample of 102 individuals, who had participated in a four-week international business study tour offered each summer over a ten-year period from 1994 to 2004, were sent questionnaires. Approximately four weeks later, a follow-up mailing was posted asking nonrespondents for their cooperation in completing the questionnaire. Sixtytwo total surveys were ultimately returned for a $61 \%$ representation, which is generally considered a good response rate in the management literature (Roth and BeVier, 1998). On average, the typical respondent was a 1998 male graduate who majored in general business.

To address the issue of possible nonresponse bias, an ANOVA between respondents from the first and second mailings was conducted. Because subjects responding to the second mailing were assumed to have responded due to increased stimuli, they were expected to be similar to nonrespondents (Armstrong, 1975). Results, however, indicated no significant differences in background or dependent variables between the two mailings, thus diminishing the probability of nonresponse bias.

\section{Measures}

The questionnaire used in this study consisted of multiple items created to measure participant reactions to the international study tour. Collectively, these items comprised two scales (cultural connectivity and professional development) that represented the dependent variables. In addition, widely recognized standardized instruments with high reliabilities were used to assess the independent variables of self-monitoring and core self-evaluations.

The cultural connectivity measure reflected the extent to which respondents interacted with host nationals, followed host customs, and assimilated into the host culture. It consisted of ten items with a 5-point Likert scale ranging from "almost no degree" to "a tremendous degree" (see Table 1). Reliability analysis on these items yielded an alpha coefficient of .71. According to Peterson (1994), alpha coefficient values of .70 or higher are acceptable for preliminary or basic research.

The extent to which respondents felt the study tour enhanced their understanding of and interest in global business, as well as their perspective on and career in the business world, was reflected in the professional development measure. This measure consisted of nine items with a 5-point Likert scale ranging from "almost no degree" to "a tremendous degree" (see Table 1). The resulting reliability analysis yielded an acceptable alpha coefficient of .82. 
Table 1: Means and Standard Deviations for Reaction Measures

\begin{tabular}{|c|c|c|}
\hline Cultural Connectivity $(\alpha=.71)$ & Mean & SD \\
\hline $\begin{array}{l}\text { To what extent did you review background information on the } \\
\text { countries and cultures visited prior to departure i.e., beyond } \\
\text { required course readings)? }\end{array}$ & 2.53 & 0.84 \\
\hline $\begin{array}{l}\text { To what extent did you visit cultural sites (e.g., museums, } \\
\text { monuments, etc.) during your "free time" on the tour? }\end{array}$ & 4.11 & 0.85 \\
\hline $\begin{array}{l}\text { To what extent did you explore "non-tourist" locations during } \\
\text { "free time" (e.g., local markets, neighborhoods, establishments)? }\end{array}$ & 3.56 & 0.93 \\
\hline $\begin{array}{l}\text { To what extent did you spend your "free time" on your own } \\
\text { (versus with the group)? }\end{array}$ & 1.82 & 0.90 \\
\hline To what extent did you socialize with local residents during "free time" & 2.24 & 0.95 \\
\hline $\begin{array}{l}\text { To what extent did you learn and use phrases (e.g., "please," } \\
\text { "thank you," etc.) in the local language? }\end{array}$ & 3.45 & 1.11 \\
\hline $\begin{array}{l}\text { To what extent did you rely on non-verbal communication when } \\
\text { interacting with local residents and merchants? }\end{array}$ & 3.24 & 0.94 \\
\hline To what extent did you follow local customs and conventions? & 3.39 & 0.82 \\
\hline $\begin{array}{l}\text { To what extent did the study tour enhance your understanding of } \\
\text { cultural differences? }\end{array}$ & 4.21 & 0.77 \\
\hline $\begin{array}{l}\text { To what extent did you discuss cultural differences with other } \\
\text { tour members during "free time"? }\end{array}$ & 3.42 & 0.95 \\
\hline \multicolumn{3}{|l|}{ Professional Development $(\alpha=.82)$} \\
\hline $\begin{array}{l}\text { To what extent did the study tour change your overall } \\
\text { business perspective? }\end{array}$ & 3.79 & 0.81 \\
\hline $\begin{array}{l}\text { To what extent did the site visits enhance your understanding of } \\
\text { global business issues? }\end{array}$ & 4.06 & 0.77 \\
\hline $\begin{array}{l}\text { To what extent did individual site visits provide significant insights } \\
\text { into a specific functional area of business (e.g., human resources, } \\
\text { marketing, finance, production, information systems, law, or strategy)? }\end{array}$ & 4.16 & 0.81 \\
\hline To what extent did you ask questions during the site visits? & 3.32 & 0.90 \\
\hline $\begin{array}{l}\text { To what extent did you discuss the presentations with other } \\
\text { tour members after the site visits? }\end{array}$ & 3.44 & 0.86 \\
\hline $\begin{array}{l}\text { To what extent did the tour enhance your interest in pursuing a job } \\
\text { involving global business? }\end{array}$ & 2.95 & 1.12 \\
\hline $\begin{array}{l}\text { To what extent was the study tour an effective format for learning } \\
\text { about business (compared to the classroom as a learning venue)? }\end{array}$ & 4.53 & 0.59 \\
\hline $\begin{array}{l}\text { To what extent was the study tour an effective format for enhancing } \\
\text { your professional development? }\end{array}$ & 4.02 & 0.97 \\
\hline To what extent has the study tour benefited you in your career? & 3.25 & 1.56 \\
\hline
\end{tabular}


The Lennox and Wolfe (1984) Revised Self-Monitoring Scale was used to assess respondents' level of self-monitoring. Research on this scale has yielded strong results regarding its reliability and dimensionality (O'Cass, 2000). Unlike Snyder's (1974) original scale, the Lennox and Wolfe (1984) revision consists of two (rather than one) factors that more clearly reflect the theory underlying self-monitoring (Shuptrine et al., 1990). Of the 12 items comprising the scale used, six reflected an individual's ability to modify self-presentation and six reflected an individual's sensitivity to the expressive behavior of others (O'Cass, 2000). Responses to the items were measured on a 5-point Likert scale ranging from "strongly disagree" to "strongly agree" (see Table 2) and yielded alpha coefficients of .79 and .72 for the two factors of self-monitoring ability and self-monitoring sensitivity, respectively.

To assess core self-evaluations, Judge et al.'s (2003) scale was used. This measure consists of 12 items with a 5-point Likert scale ranging from "strongly disagree" to "strongly agree" (see Table 3). In previous research, the scale has displayed acceptable levels of internal consistency and test-retest reliability, with the 12 items loading on a one-dimensional construct. Furthermore, it has displayed convergent validity as evidenced by its correlations with the four core traits of self-esteem, neuroticism, generalized self-efficacy, and locus of control (Judge et al., 2003). The reliability of the measure was affirmed in the present study with an alpha coefficient of .83 .

In addition to the aforementioned measures, the questionnaire also included open-ended questions about the impact of the tour on respondents, as well as questions regarding relevant background information. The background questions addressed gender, year of participation on the tour, and college major.

\section{Res u I t s}

Table 4 provides descriptive statistics and zero-order correlations for all variables. With regard to background variables, only college major correlated with other variables in the study. It should be noted, however, that this variable was skewed in that over $82 \%(\mathrm{n}=51)$ of the respondents were general business majors, with the remaining $18 \%$ distributed across finance $(n=6)$, accounting $(n=2)$, and liberal arts $(n=3)$ majors. Of the remaining correlations among the variables of analysis, no correlation exceeded .66; thus, multicollinearity did not appear to pose a serious problem (Billings and Wroten, 1978; Mathieu and Hamel, 1989).

The means for individual items used to measure participants' reactions to the study tour are shown in Table 1. Reaction measures such as these are among the most popular internal criteria for assessing training effectiveness (French, 
Table 2: Means and Standard Deviations for Self-Monitoring

\begin{tabular}{|l|c|c|}
\hline Self-Monitoring Ability ( $\alpha=.79)$ & Mean & SD \\
\hline $\begin{array}{l}\text { I have the ability to control the way I come across to people, } \\
\text { depending on the impression I wish to give them. }\end{array}$ & 4.23 & 0.64 \\
\hline $\begin{array}{l}\text { Once I know what a situation calls for, it's easy for me to regulate } \\
\text { my actions accordingly. }\end{array}$ & 4.31 & 0.53 \\
\hline $\begin{array}{l}\text { When I feel that the image I am portraying isn't working, } \\
\text { I can readily change it to something that does. }\end{array}$ & 3.68 & 0.72 \\
\hline $\begin{array}{l}\text { I have trouble changing my behavior to suit different people } \\
\text { and different situations.* }\end{array}$ & 4.11 & 0.63 \\
\hline $\begin{array}{l}\text { I have found that I can adjust my behavior to meet the requirements } \\
\text { of any situation in which I find myself. }\end{array}$ & 4.21 & 0.73 \\
\hline $\begin{array}{l}\text { In social situations, I have the ability to alter my behavior if I feel } \\
\text { that something else is called for. }\end{array}$ & 4.11 & 0.58 \\
\hline Self-Monitoring sensitivity $(\alpha=.72)$ & & 0.76 \\
\hline $\begin{array}{l}\text { In conversations, I am sensitive to even the slightest change } \\
\text { in the facial expression of the person with whom I am conversing. }\end{array}$ & 4.10 & 0.76 \\
\hline $\begin{array}{l}\text { I can usually tell when I've said something inappropriate by reading } \\
\text { it in the listener's eyes. }\end{array}$ & 4.16 & 0.58 \\
\hline $\begin{array}{l}\text { My powers of intuition are quite good when it comes to understanding } \\
\text { the emotions and motives of others. }\end{array}$ & 4.00 & 0.77 \\
\hline $\begin{array}{l}\text { I can usually tell when others consider a joke to be in bad taste, } \\
\text { even though they may laugh convincingly. }\end{array}$ & 3.79 \\
\hline $\begin{array}{l}\text { I am often able to read people's true emotions correctly } \\
\text { (through their eyes). }\end{array}$ & 0.63 \\
\hline $\begin{array}{l}\text { If someone is lying to me, I usually know it at once from } \\
\text { that person's manner of expression. }\end{array}$ & 3.66 & 0.75 \\
\hline
\end{tabular}


Table 3: Means and Standard Deviations for Core Self-Evaluation

\begin{tabular}{|c|c|c|}
\hline I am confident I get the success I deserve in life. & 3.88 & 0.66 \\
\hline Sometimes I feel depressed.* & 3.39 & 1.08 \\
\hline When I try, I generally succeed. & 4.29 & 0.55 \\
\hline Sometimes when I fail I feel worthless.* & 3.76 & 1.02 \\
\hline I complete tasks successfully. & 4.32 & 0.54 \\
\hline Sometimes, I do not feel in control of my work.* & 3.34 & 1.14 \\
\hline Overall, I am satisfied with my work. & 4.06 & 0.65 \\
\hline I am filled with doubts about my competence.* & 4.29 & 0.78 \\
\hline I determine what will happen in my life. & 4.00 & 0.81 \\
\hline I do not feel in control of my success in my career.* & 4.21 & 0.73 \\
\hline I am capable of coping with most of my problems. & 4.29 & 0.52 \\
\hline There are times when things look pretty bleak and hopeless to me.* & 4.15 & 0.88 \\
\hline
\end{tabular}
Items

*Reverse scored

Table 4: Means, Standard Deviations, and Correlations for All Variables

\begin{tabular}{|l|l|l|c|c|c|c|c|c|c|}
\cline { 2 - 10 } \multicolumn{1}{c|}{} & Mean & SD & 1 & 2 & 3 & 4 & 5 & 6 & 7 \\
\hline 1. Cultural Connectivity & 31.98 & 4.78 & $(.71)^{\mathrm{a}}$ & & & & & & \\
\hline 2. Professional Development & 33.48 & 5.18 & $0.33 * *$ & $(.82)$ & & & & & \\
\hline 3. Self-Monitoring Ability & 24.65 & 2.69 & $0.43 * *$ & 0.04 & $(.79)$ & & & & \\
\hline 4. Self-Monitoring Sensitivity & 23.16 & 2.74 & $0.24 *$ & 0.18 & $0.58 * *$ & $(.72)$ & & & \\
\hline 5. Core Self-Evaluations & 47.98 & 5.66 & 0.06 & 0.03 & $0.45 * *$ & 0.20 & $(.83)$ & & \\
\hline 6. Year Abroad & 1998 & 2.11 & 0.20 & -0.03 & 0.08 & 0.04 & -0.13 & & \\
\hline 7. Gender & 1.31 & 0.46 & -0.06 & 0.08 & -0.10 & 0.18 & 0.03 & 0.04 & \\
\hline 8. College Major & 1.35 & 0.94 & 0.10 & -0.06 & $-.32 * *$ & -0.19 & $-.29 *$ & $.28 *$ & 0.20 \\
\hline
\end{tabular}

${ }^{a}$ Numbers in parentheses are reliability coefficients

$* *$ Correlation is significant at the 0.01 level (1-tailed)

*Correlation is significant at the 0.05 level (1-tailed). 
Frontiers: The Interdisciplinary Journal of Study Abroad

Table 5: Means and Standard Deviations of Median Splits

\begin{tabular}{|c|c|c|c|}
\hline & $\begin{array}{l}\text { High self-monitoring } \\
\text { ability }\end{array}$ & $\begin{array}{l}\text { Low self-monitoring } \\
\text { ability }\end{array}$ & $\mathbf{F}$ \\
\hline \multicolumn{4}{|l|}{ Cultural Connectivity } \\
\hline $\mathrm{M}$ & 33.69 & 30.17 & $9.57 * *$ \\
\hline SD & 4.64 & 4.30 & \\
\hline \multicolumn{4}{|l|}{ Professional Development } \\
\hline M & 33.78 & 33.15 & 0.22 \\
\hline \multirow[t]{2}{*}{ SD } & 5.72 & 4.55 & \\
\hline & $\begin{array}{l}\text { High self-monitoring } \\
\text { sensitivity }\end{array}$ & $\begin{array}{l}\text { Low self-monitoring } \\
\text { sensitivity }\end{array}$ & $\mathrm{F}$ \\
\hline \multicolumn{4}{|l|}{ Cultural Connectivity } \\
\hline $\mathrm{M}$ & 32.92 & 30.60 & $3.66 *$ \\
\hline SD & 4.70 & 4.65 & \\
\hline \multicolumn{4}{|l|}{ Professional Development } \\
\hline $\mathrm{M}$ & 34.81 & 31.50 & $6.41 *$ \\
\hline \multirow[t]{2}{*}{ SD } & 5.26 & 4.45 & \\
\hline & $\begin{array}{c}\text { High core } \\
\text { self-evaluations }\end{array}$ & $\begin{array}{c}\text { Low core } \\
\text { self-evaluations }\end{array}$ & $\mathrm{F}$ \\
\hline \multicolumn{4}{|l|}{ Cultural Connectivity } \\
\hline $\mathrm{M}$ & 32.36 & 31.55 & 0.51 \\
\hline SD & 4.80 & 4.81 & \\
\hline \multicolumn{4}{|l|}{ Professional Development } \\
\hline $\mathrm{M}$ & 33.81 & 33.11 & 0.60 \\
\hline SD & 4.97 & 5.47 & \\
\hline
\end{tabular}


2003; Ivancevich, 1998). It is interesting to note that in this study, over half of the individual questions (before being combined into scales) elicited relatively strong or weak reactions among trainees/participants.

Six of the 19 items were rated relatively high by participants (i.e., greater than 4 on a 5-point scale). These included the extent to which: the tour was an effective format for learning about business (compared to the classroom as a learning venue) $(x=4.53)$; the study tour enhanced their understanding of cultural differences $(\mathrm{x}=4.21)$; the site visits provided significant insights into a functional area of business $(\mathrm{x}=4.16)$; they visited cultural sites (e.g., museums, monuments, etc.) during their "free time" $(\mathrm{x}=4.11)$; the corporate site visits enhanced their understanding of global business issues ( $\mathrm{x}=4.06)$; and the tour was an effective format for enhancing their professional development $(\mathrm{x}=4.02)$.

There were four items that were rated relatively low (i.e., less than 3 on a 5-point scale). These included the extent to which: the tour enhanced their interest in pursuing a job involving global business $(\mathrm{x}=2.95)$; they reviewed background information on the countries and cultures visited prior to departure (i.e., beyond required course readings) $(x=2.53)$; they socialized with local residents during "free time" $(\mathrm{x}=2.24)$; and they spent their "free time" on their own (versus with the group) $(\mathrm{x}=1.82)$.

\section{Test of H y oth e ses}

Hypotheses 1 and 2 stated that, compared to lower self-monitoring participants, high self-monitoring participants would experience greater cultural connectivity and professional development, respectively. One-tailed correlational tests indicated a significant, positive correlation between cultural connectivity and both self-monitoring ability $(\mathrm{r}=.43, \mathrm{p}<.01)$ and self-monitoring sensitivity $(\mathrm{r}=.24, \mathrm{p}<.05)$. No significant relationship was found between professional development and either self-monitoring scale; however, the correlation between self-monitoring sensitivity and professional development $(r=.18)$ approached significance at the $\mathrm{p}<.10$ level (See Table 4).

Consistent with past research on self-monitoring (e.g., Snyder and Monson, 1975; Caligiuri and Day, 2000), a median split procedure was performed. Respondents with self-monitoring scores above the median were categorized as high selfmonitors and those below the median were categorized as low self-monitors.

One-way ANOVA results fully supported the first hypothesis for both self-monitoring ability and self-monitoring sensitivity. Respondents with high self monitoring ability $(\mathrm{x}=33.69$, $\mathrm{sd}=4.64)$ were significantly different from those with lower self-monitoring ability $(\mathrm{x}=30.17, \mathrm{sd}=4.30)$ on cultural 
Frontiers: The Interdisciplinary Journal of Study Abroad

Table 6: Factor Loadings for Post Hoc Analysis

\begin{tabular}{|ll|}
\hline & Factor Loadings \\
\hline Factor one: Core self-assurance $(\alpha=.78)$ & 0.41 \\
\hline Sometimes I feel depressed. & 0.75 \\
\hline Sometimes when I fail I feel worthless. & 0.53 \\
\hline Sometimes, I do not feel in control of my work. & 0.76 \\
\hline I am filled with doubts about my competence. & 0.48 \\
\hline I am capable of coping with most of my problems. & 0.81 \\
\hline There are times when things look pretty bleak and hopeless to me. & \\
\hline & 0.52 \\
\hline Factor two: Core self-determination ( $\alpha=.74)$ & 0.73 \\
\hline I am confident I get the success I deserve in life. & 0.55 \\
\hline When I try, I generally succeed. & 0.69 \\
\hline I complete tasks successfully. & 0.59 \\
\hline Overall, I am satisfied with my work. & \\
\hline I do not feel in control of my success in my career. & \\
\hline
\end{tabular}

Table 7: Means and Standard Deviations of Post Hoc Median Splits

\begin{tabular}{rccc} 
& $\begin{array}{c}\text { High core } \\
\text { self-assurance }\end{array}$ & $\begin{array}{c}\text { Low core } \\
\text { self-assurance }\end{array}$ & F \\
\hline Cultural Connectivity & & & \\
S & 32.29 & 31.50 & 0.40 \\
Professional Development & 4.64 & 5.06 & \\
M & 33.65 & 33.22 & 0.10 \\
SD & 5.14 & 5.34 & \\
\hline & High core & Low core & \\
\hline Cultural Connectivity & self-determination & self-determination & F \\
M & 31.78 & & \\
SD & 4.78 & 32.56 & 0.31 \\
Professional Development & & 4.88 & \\
SD & 34.13 & 31.53 & $2.9^{*}$ \\
\end{tabular}

* Correlation is significant at the 0.05 level (1-tailed) 
connectivity $(\mathrm{F}[1,60]=9.57, \mathrm{p}<.01)$. Similarly, respondents with high selfmonitoring sensitivity $(\mathrm{x}=32.92$, $\mathrm{sd}=4.70)$ were significantly different from those with lower self-monitoring sensitivity $(\mathrm{x}=30.60$, $\mathrm{sd}=4.65)$ on cultural connectivity $(\mathrm{F}[1,60]=3.66, \mathrm{p}<.05)$. (see Table 5)

The second hypothesis was only partially supported by ANOVA. Respondents with high self-monitoring sensitivity $(x=34.81$, $s d=5.26)$ were significantly different from those with lower self-monitoring sensitivity $(\mathrm{x}=$ $31.50, \mathrm{sd}=4.45)$ on professional development $(\mathrm{F}[1,58]=6.41, \mathrm{p}<.01)$. No significant difference, however, was found between respondents with high selfmonitoring ability $(x=33.78$, sd $=5.72)$ and those with lower self-monitoring ability $(\mathrm{x}=33.14, \mathrm{sd}=4.55)$ in terms of professional development $(\mathrm{F}[1,58]$ $=.22$, ns) (see Table 5).

Hypotheses 3 and 4 stated that, compared to participants with lower core self-evaluations, participants with high core self-evaluations would demonstrate greater cross-cultural connectivity and professional development, respectively. One-tailed correlational tests indicated no significant results for either hypothesized relationship.

Consistent with the procedure for self-monitoring, a median split procedure was performed in which respondents with core self-evaluations above the median were categorized as having high core self-evaluations and those below the median were categorized as having low core self-evaluations. One-way ANOVA results did not support either the third or fourth hypothesis. There were no significant differences between those with high core self-evaluations and those with low core self-evaluations on either cultural connectivity or professional development (see Table 5).

\section{Post Hoc Analysis}

Given the lack of significant results for core self-evaluations and the relatively recent development of the associated scale (Judge et al., 2003), additional analysis was conducted. Per Conway and Huffcutt (2003), exploratory factor analysis was performed on the scale items using the maximum likelihood model and an oblique rotation, with two factors specified for extraction based on multiple criteria (i.e., large eigenvalues, percentage of variance accounted for, and examination of multiple solutions and their interpretability). The two resultant factors had eigenvalues of 4.45 (37.11\% of variance) and 1.34 $(11.54 \%)$ with one item excluded because it failed to load at the .40 level or higher on either factor (Sherer, Maddux, Mercandante, Prentice-Dunn, Jacobs, and Rogers, 1982) (see Table 6). 
The first factor (labeled self-assurance) consisted of six items that seemed to reflect aspects of self-esteem and neuroticism. Reliability analysis on these items yielded an acceptable alpha coefficient of .78. The remaining five items comprising the second factor (labeled self-determination) seemed to reflect aspects associated with generalized self-efficacy and locus of control. The resulting reliability analysis on this factor also yielded an acceptable alpha coefficient of .74 (see Table 6).

Consistent with prior procedures of doing median splits on independent variables, respondents with scores about the median on each factor were categorized as high on that factor, with those below the median categorized as low. One-way ANOVA results indicated only one significant difference, which was associated with the second factor. Respondents with high self-determination $(x=34.13, \mathrm{sd}=5.09)$ were significantly different from those with lower selfdetermination $(\mathrm{x}=31.53$, sd $=5.11)$ on the dependent variable of professional development $(\mathrm{F}[1,58]=2.93, \mathrm{p}<.05)$ (see Table 7).

\section{D i s c us sion}

The purpose of this research was to investigate the perceived effectiveness of international business study tours and the associated impact of two personality variables - self-monitoring and core self-evaluations. Reaction measures from study tour participants were strong, indicating that the tours were effective in facilitating cultural connectivity and enhancing professional development; however, only self-monitoring proved to have a significant impact on both measures. Nevertheless, post hoc analysis did reveal that a subfactor of core self-evaluations (i.e., core self-determination) had a significant impact on professional development.

Among the notably strong reactions, participants indicated that the study tour greatly enhanced their understanding of cultural differences, with the site visits providing valuable insights into both global business and the functional areas of business. They also noted that the tour was a very effective format for learning about business (as compared to the classroom as a learning venue) and for enhancing their professional development. Furthermore, they made good use of their "free time" with other participants by visiting cultural sites such as museums and monuments. Most surprisingly, however, they indicated that the study tour had only a moderate impact on their interest in pursuing a job involving global business. One explanation for this finding may be that many of these participants, who purposely chose a short summer sojourn rather than an extended semester abroad, were interested in exposure to, but not immersion in, global business abroad. 
As predicted, self-monitoring had a significant impact on cultural connectivity. Both factors which comprise self-monitoring — ability and sensitivity — indicated a significant, positive correlation with cultural connectivity. Furthermore, participants who ranked high on each factor demonstrated significantly stronger connectivity than those who ranked low. These results support prior research on self-monitoring (Caldwell and O'Reilly, 1982; Caligiuri and Day, 2000; Harrison et. al., 1996) which suggests that this personality trait impacts both cross-cultural interactions and assimilation.

Although self-monitoring ability was not a factor in professional development, participants with high self-monitoring sensitivity reported significantly greater professional development than those with low self-monitoring sensitivity. The surprising lack of a relationship between self-monitoring ability and professional development may be explained by the difference between perceptions and actions. The items representing professional development in this study included perceptions related to self-improvement rather than actions involving changes in self-presentation (i.e., self-monitoring ability). Correspondingly, the significant difference between participants with high and low self-monitoring sensitivity may be explained by the former's greater perceptivity to environmental cues which more strongly influenced their interest in and understanding of global business (i.e., their professional development).

The absence of a relationship between core self-evaluations and either cultural connectivity or professional development was most surprising. One explanation for this absence may be that, as noted previously, the scale used in this study is relatively new (Judge et al., 2003), thus warranting further analysis as a construct. This conclusion is supported, in part, by the post hoc analysis conducted in this study which found two factors associated with the scale rather than the unidimensionality indicated in prior research. Nevertheless, only one of the two factors proved relevant. Participants labeled with high self-determination reported greater professional development than those labeled with low self-determination. It seems highly determined participants strive more fully to enhance their global awareness and appreciation, thus facilitating their professional development.

At least two limitations should be kept in mind regarding the findings in this study. The first limitation involves the respondents. Although the sample represented nine separate study tours, all of the respondents were from the same university (with $95 \%$ from its business school) and under the tutelage of the same professor. Hence, the results may have limited generalizability.

The second limitation involves the measures used. Because this study relied on self-report instruments for all variables, some problems of common 
method variance may have occurred. Nevertheless, in an effort to minimize these potential problems, the measures of independent and dependent variables were placed on separate pages of the questionnaire.

Despite these limitations, the findings are suggestive of at least three important implications. First, the results lend support to the value of study tours as positive and beneficial learning experiences for participants. With the exception of one article (i.e., Schuster, 1993), previous research has focused only on the design and development of such tours, not on the perceived outcomes. This study suggests that there are at least two meaningful categories of outcomes - cultural connectivity and professional development.

Second, the strong relationships found between self-monitoring and the outcome measures suggest that this personality trait may inform the selection and/or training of prospective participants. Knowing that high self-monitors demonstrate stronger cultural connectivity and greater professional development may lead instructors to assess this trait among applicants and to choose those high on self-monitoring for participation. Alternatively, knowing that low self-monitors may be more challenged in their cultural connectivity and professional development, instructors can provide such participants with additional insight, guidelines, and coaching on how to enact more self-monitoring behaviors, despite their predisposition not to modify their self-presentation or to recognize the expressive behavior of others.

Last, this study suggests that additional research is needed on the construct of core self-evaluations, especially in cross-cultural research on expatriates and sojourners. Given the seemingly logical relationship between this construct and both cultural connectivity and professional development, it is surprising that only one relationship was found through post hoc analysis. Also, future studies might consider the effectiveness of study tours in light of other personality variables, such as self-consciousness (Gudykunst et al., 1987) or psychological hardiness (Cole, Field, and Harris, 2004). 


\section{J. Kline Harison}

\section{R e f e r e n c e s}

Allen, D., \& Young, M. (1997). From tour guide to teacher: Deepening crosscultural competence through international experience-based education. Journal of Management Education, 21(2), 168-189.

Armstrong, J., \& Overton, T. (1977). Estimating nonresponse bias in mail surveys. Journal of Marketing Research, 14, 396-402.

Billings, R.S., \& Wroten. S.P. (1978). Use of path analysis in industrial/organizational psychology: Criticisms and suggestions. Journal of Applied Psychology, 63, 677-688.

Boudreau, J. W., Boswell, W. R., Judge, T. A., \& Bretz Jr., R. D. (2001). Personality and cognitive ability as predictors of job search among employed managers. Personnel Psychology, 54(1), 25-26.

Brokaw, S. C. (1996). Planning, organizing, and executing short term international exposures for U.S. students of marketing and business: An alternative method. Marketing Education Review, 6(3), 87-93.

Business students flock to DePaul study abroad seminars in Cuba, Chile, Greece, Thailand, Hong Kong in December. (2002, November 18). AScribe Newswire.

Caldwell, D., \& O'Reilly, C. (1982). Boundary spanning and individual performance: The impact of self-monitoring. Journal of Applied Psychology, $16,124-127$.

Caligiuri, P. M., \& Day, D. V. (2000). Effects of self-monitoring on technical, contextual, and assignment-specific performance. Group E Organization Management, 25(2), 154-174.

Cole, M. S., Field, H. S., \& Harris, S. G. (2004). Student learning motivation and psychological hardiness: Interactive effects on students' reactions to a management class. Academy of Management Learning and Education, 3(1), 64-85.

Conway, J. M., \& Huffcutt, A. I. (2003). A review and evaluation of exploratory factor analysis practices in organizational research. Organizational Research Methods, 6(2), 147-168.

Day, D. V., Unckless, A. L., Schleicher, D. J., \& Hiller, N. J. (2002). Selfmonitoring personality at work: A meta-analytic investigation of construct validity. Journal of Applied Psychology, 87(2), 390-401.

Duke, C. R. (2000). Study abroad learning activities: A synthesis and comparison. Journal of Marketing Education, 22(2), 155-165.

French, W. L. (2003). Human resources management. Boston: Houghton Mifflin Company. 
Gordon, P. \& Smith, D.K. (1992). Planning, organizing, and executing short term international exposures for U.S. students of marketing and business. Marketing Education Review, 2, 47-53.

Gudykunst, W. B., Yang, S., \& Nishida, T. (1987). Cultural differences in selfconsciousness and self-monitoring. Communication Research 14(1), 7-34.

Harrison, J. K., Chadwick, M., \& Scales, M. (1996). The relationship between cross-cultural adjustment and the personality variables of self-efficacy and self-monitoring. International Journal of Intercultural Relations, 20(2), $167-188$.

Harter, S. (1990). Causes, correlates, and the functional role of global selfworth: A life-span perspective. In R. J. Sternberg \& J. Kolligan, Jr. (Eds.), Competence considered (pp. 67-97). New Haven: Yale University Press.

Ickes, W., \& Barnes, R. (1977). The role of sex and self-monitoring on unstructured dyadic interaction. Journal of Personality and Social Psychology, 35, $315-330$.

Institute of International Education. (2003) American students study abroad in growing Numbers (November 17). www.Opendoors.iienetwork.org.

Ivancevich, J. M. (1998). Human resource management. Boston: Irwin/McGrawHill.

Jenkins, M. J. (1993). Self-monitoring and turnover: The impact of personality on intent to leave. Journal of Organizational Behavior, 14(1), 83-91.

Johnson, E. C., Krist Of-Brown, A. L., Van Vianen, A. E. M., De Pater, I., \& Rigsby, M. M. (2002). Expatriate social ties: The impact of relationships with comparable others and host country nationals. Academy of Management Proceedings, $p H 1,6 \mathrm{p}$.

Judge, T. A., Erez, A., Bono, J. E., \& Thoresen, C. J. (2003). The core selfevaluations scale: Development of a measure. Personnel Psychology, 56(2), 303-331.

Judge, T. A., Locke, E. A., Durham, C. C. (1997). The dispositional causes of job satisfaction: A core evaluations approach. Research in Organizational Behavior, 19, 151-188.

Judge, T. A., Locke, E. A., Durham, C. C., \& Kluger, A. N. (1998). Dispositional effects on job and life satisfaction: The role of core evaluations. Journal of Applied Psychology, 83(1), 17-34.

Lennox, R. D., \& Wolfe, R. N. (1984). Revision of the self-monitoring scale. Journal of Personality and Social Psychology, 46(6), 1349-1364. 


\section{J. KIine Harison}

Mathieu, J.E., \& Hamel, K. (1989). A causal model of the antecedents of organizational commitment among professionals and nonprofessionals. Journal of Vocational Behavior, 34, 299-317.

Mehra, A., Kilduff, M., \& Brass, D. J. (2001). The social networks of high and low self-monitors: Implications for workplace performance. Administrative Science Quarterly, 46, 121-146.

O'Cass, A. (2000). A psychometric evaluation of a revised version of the Lennox and Wolfe revised self-monitoring scale. Psychology \& Marketing, 17(5), 397-419.

Packer, E. (1985). Understanding the subconscious. The Objectivist Forum, 6(1), $1-10$ and $6(2), 8-15$.

Peterson, R. A. (1994). A meta-analysis of Cronbach's coefficient alpha. Journal of Consumer Research, 21, 381-391.

Porth, S. J. (1997). Management education goes international: A model for designing and teaching a study tour course. Journal of Management Education, 21(2), 190-199.

Roth, P. L., \& BeVier, C. A. (1998). Response rates in HRM/OB survey research: Norms and correlates, 1990-1994. Journal of Management, 24(1).

Schuster, C. P. (1993). Planning and implementing overseas travel classes for executive MBA students. Marketing Education Review, 3, 54-60.

Sherer, M., Maddux, J. E., Mercandante, B., Prentice-Dunn, S., Jacobs, B., \& Rogers, R. W. (1982). The self-efficacy scale: Construction and validation. Psychological Reports, 51, 663-671.

Shuptrine, F. K., Bearden, W. O., \& Teel, J. E. (1990). An analysis of the dimensionality and reliability of the Lennox and Wolfe revised self-monitoring scale. Journal of Personality Assessment, 54(3\&4), 515-522.

Snyder, M. (1974). Self-monitoring of expressive behavior. Journal of Personality and Social Psychology, 30(4), 526-537.

Snyder, M., \& Monson, T. C. (1975). Persons, situations, and the control of social behavior. Journal of Personality and Social Psychology, 32(4), 637-644.

Snyder, M. (1987). Public appearances private realities: The psychology of selfmonitoring. New York: W.H. Freeman and Company.

Tharenou, P. (1979). Employee self-esteem: A review of the literature. Journal of Vocational Behavior, 15, 316-346. 